\title{
Preparation single layer of (MgO) as antireflection coating using PLD
}

\section{technique}

\author{
Kadhim A. Aadim¹, Alaa Nazar Abd Algaffar², Sanar Najim Abdullah ${ }^{2}$ \\ ${ }^{1}$ Department of Physics, College of Sciences, University of Baghdad, Baghdad \\ ${ }^{2}$ Department of Physics, College of Sciences for women, University of Baghdad \\ E-mail: kadhim_adem@scbaghdad.edu.iq
}

\begin{abstract}
In this work preparation of antireflection coating with single layer of $\mathrm{MgO}$ using pulsed laser deposition (PLD) method which deposit on glass substrate with different thicknesses (90 and 100) $\mathrm{nm}$ annealed at temperature $500 \mathrm{~K}$ was done.

The optical and structural properties (X-ray diffraction) have been determined. The optical reflectance was computed with the aid of MATLAB over the visible and near infrared region. Results shows that the best result obtained for optical performance of AR'Cs at 700 shots with thickness $90 \mathrm{~nm}$ nanostructure single layer AR'Cs and low reflection at wavelength $550 \mathrm{~nm}$.
\end{abstract}

Key words

Antireflection

coating, PLD

technique, $\mathrm{MgO}$,

optical properties.

\section{Article info.}

Received: Apr. 2017

Accepted: May. 2017

Published: Mar. 2018

$$
\begin{aligned}
& \text { تحضير غشاء مضاد للانعكاس احادي الطبقة من اوكسبد المغتسيوم باستخدام تقانة الترسيب } \\
& \text { بالليزر النبضي } \\
& \text { كاظم عبد الواحد عادم، الاء نزار عبد الغفار² سنر نجم عبد الله2 }
\end{aligned}
$$

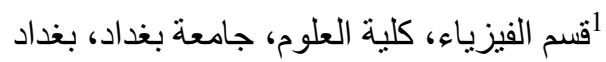

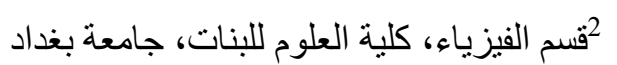

الخلاصة في هذا البحث تم تحضير طلاء مضاد للانعكاس احادي الطبقة لمادة اوكسيد المغنسيوم بطريقة الترسيب

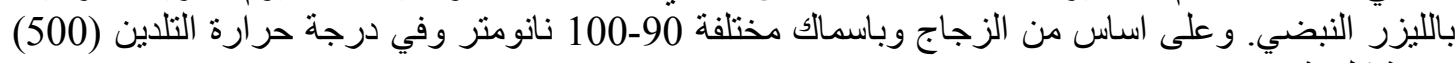
د مرجة كلفنية.

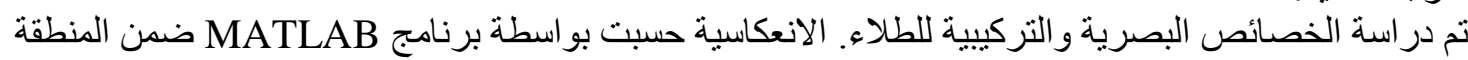

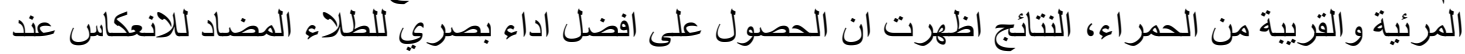

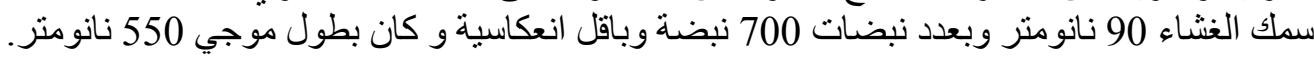

\section{Introduction}

Optical systems consist of a large part of a series of surfaces that are the boundaries between different materials. The optical coating is very important technologically to modem optics [1]. One type of the most important optical coating is an antireflection coating [2]. Antireflection coating work the opposite of a reflector. At the principal wavelength, it creates destructive interference for the multiple reflected waves, and constructive interference for the multiple transmitted waves[3] .This type of coating is commonly applied to the surfaces of optical components such as lenses, mirrors, and windows. When deposited on the surface of 
an interference filter, $A R^{\prime} C$ increases transmission and reduces the reflection [4].

$\mathrm{MgO}$ is a promising candidate for a variety of new applications, such as in lighting industry, optical systems, and laser technology, control technology, as well as creation thermal sensors. Furthermore the computed has been applied as a protective and antireflection layer [5, 6].

There are various methods for obtaining $\mathrm{MgO}$ films such as metal organic molecular beam epitaxy [7], vapor phase epitaxy [8], sol-gel syntheses, reactive sputtering [9], pulse laser deposition [10], and chemical vapor deposition [11].

\section{Basic theoretical}

\section{1. characteristic matrix}

The tangential of electric $E$ and magnetic $H$ components are shown in Fig. 1. The characteristic matrix for thin film single layer is [12].

$$
\left(\begin{array}{l}
B \\
C
\end{array}\right)=\left(\begin{array}{cc}
\cos \delta & i \sin \delta \\
i N_{1} \sin \delta & \cos \delta
\end{array}\right)\left(\begin{array}{c}
1 \\
N_{s}
\end{array}\right)
$$

where

$\left(\begin{array}{l}B \\ C\end{array}\right)$ is defined as the characteristic matrix of the assembly.

$\delta=2 \pi \mathrm{N}_{1} \mathrm{~d} / \lambda \quad$ (phase thickness)

$\lambda=$ design wave length

$N_{1}=$ refractive index of coating material, $\left(\mathrm{N}_{1}=\mathrm{n}\right.$-ik $) \mathrm{n}$ as the real part of the refractive index and $(\mathrm{k})$ as the extinction coefficient.

$\mathrm{d}=$ thickness of layer coating .

$N_{S}=$ refractive index of substrate.

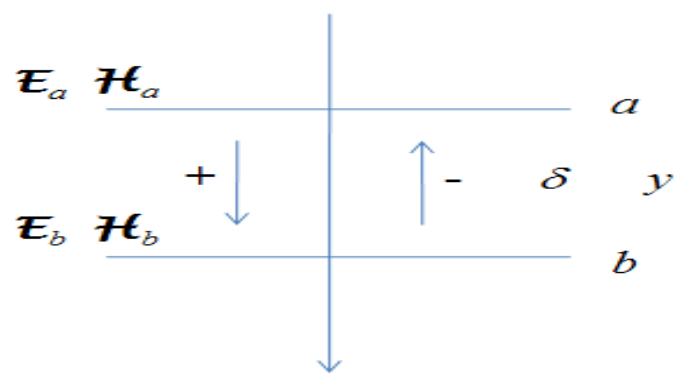

Fig.1: The components electric $E$ and magnetic $\mathrm{H}$ waves.
Therefore, we can write the reflectance $(\mathrm{R})$, the transmittance (T) and absorbance (A) in terms of B and C as follow [12].

$R=\left(\frac{N_{0} B-C}{N_{0} B+C}\right)\left(\frac{N_{0} B-C}{N_{0} B+C}\right)^{*}$

$T=\frac{4 N_{0} R_{e}\left(N_{S}\right)}{\left(N_{\mathrm{o}} B+C\right)\left(N_{\mathrm{o}} B+C\right)^{*}}$

$A=\frac{4 N_{\mathrm{o}} R_{e}\left(B C^{*}-N_{S}\right)}{\left(N_{\mathrm{o}} B+C\right)\left(N_{\mathrm{o}} B+C\right)^{*}}$

when $N_{0}=$ is the refractive index of air (or the incident medium).

The extinction coefficient $\mathrm{k}$, which is related to the exponential decay of the wave as it passes through the medium, is defined as $[13,14]$ :

$\mathrm{k}=\frac{\alpha \lambda}{4 \pi}$

where $(\lambda)$ is the wavelength of the incident radiation and $(\alpha)$ is the Absorption Coefficient.

$\alpha=2.303 \frac{A}{d}$

(A) is the absorbance,(d) thickness of layer coating.

When the fall of the rays of monochromatic light a section vertically from the surface, the part of this reflected beam $(\mathrm{R})$, and part of it is absorbed and run out the remaining portion $(\mathrm{T})$ of the film. And related to the absorbance $(\mathrm{A})$ reflectivity $(\mathrm{R})$ and transmittance $(\mathrm{T})$ as in the following relationship [15].

$\mathrm{A}+\mathrm{R}+\mathrm{T}=1$

\section{Experimental part}

Fixed conditions for prepared $\mathrm{MgO}$ thin films include Q-switching $\mathrm{Nd}$ : YAG laser beam energy pulse $(500 \mathrm{~mJ})$, Pressure $\left(8 \times 10^{-2} \mathrm{mbar}\right)$, pulse width (10ns), repetition frequency $(6 \mathrm{~Hz})$ and rotating of target $(3 / \mathrm{min})$, and the preparation conditions using variation number of shots (700 and 800).

The glass substrate was cleaning in the ultrasonic baths of acetone and 
alcohol, putting substrate on holder inside the chamber, putting a target in target holder, closing chamber and evacuating the air from inside the deposition chamber. The pressure reach $10^{-2}$ mbar. Focusing Nd:YAG SHG Q-switching laser beam coming through a window is incident on the target surface making an angle of $45^{\circ}$ with it.

$\mathrm{MgO}$ thin films exposed for annealing temperature at $500 \mathrm{~K}$ and for 3 hours to get the structural stability of these thin films.

The optical properties of the $\mathrm{MgO}$ thin films was determined by the UVVIS spectrum (Optima Sp - 300 Plus), used to determined absorbance and transmittance.

The structural characterization determined by Rigaku Miniflex X- ray diffraction meter of $1.54 \AA$.

\section{Results and discussion}

1. Optical properties

The transmittance spectra of $\mathrm{MgO}$ films for different thicknesses (90 and 100) $\mathrm{nm}$ have been determined by UVVisible transmission spectrum in the spectral range (400-1100) $\mathrm{nm}$ and annealed at temperature $500 \mathrm{~K}$ are shown in Fig. 2.

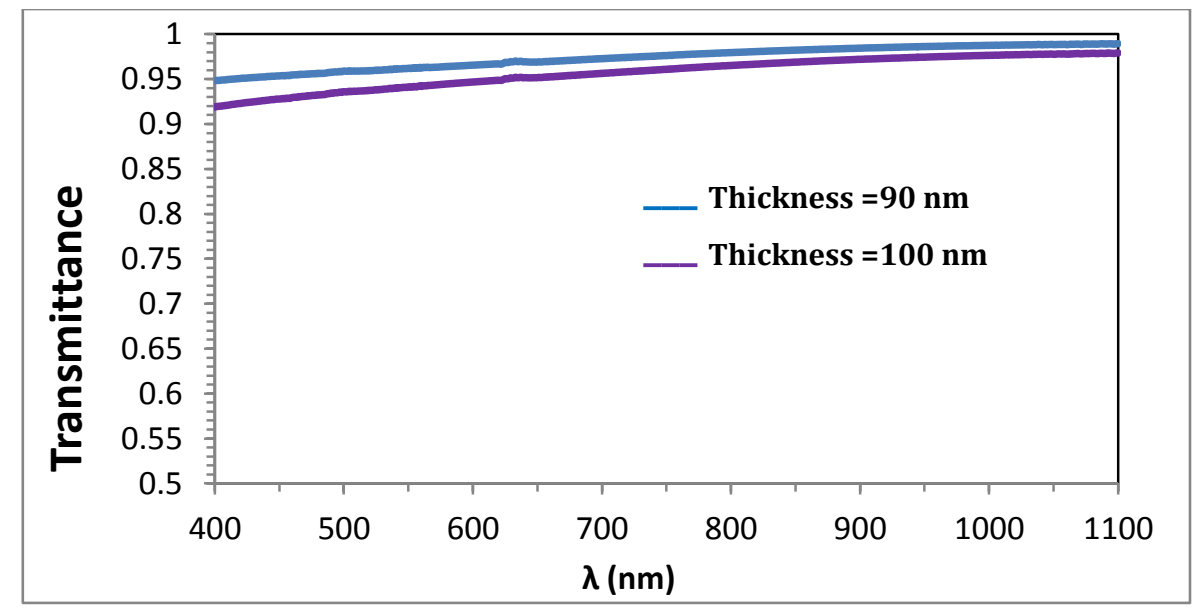

Fig. 2: Transmittance as a function of wavelength for $\mathrm{MgO}$ films for different thicknesses $(90$ and $100 \mathrm{~nm})$.

The average transmittance in the spectra (400-1100nm) is about (91$97 \%$ ). It is observed that the optical transmittance decreases slightly with increasing of film thickness. The optical transmission is above $97 \%$ for $\mathrm{MgO}$ thin film with $90 \mathrm{~nm}$ thick, which decreased to $91 \%$ upon increasing the thickness to $100 \mathrm{~nm}$. This behavior is attributed to increase the number of atoms with increasing the thickness which leads to increase the number of collision between incident radiation and atoms, and this leads to increase absorbance and decreasing transmittance.

The absorbance spectra of $\mathrm{MgO}$ thin film in the spectral range (400-1100) $\mathrm{nm}$ on glass substrate are shown in Fig. 3. 


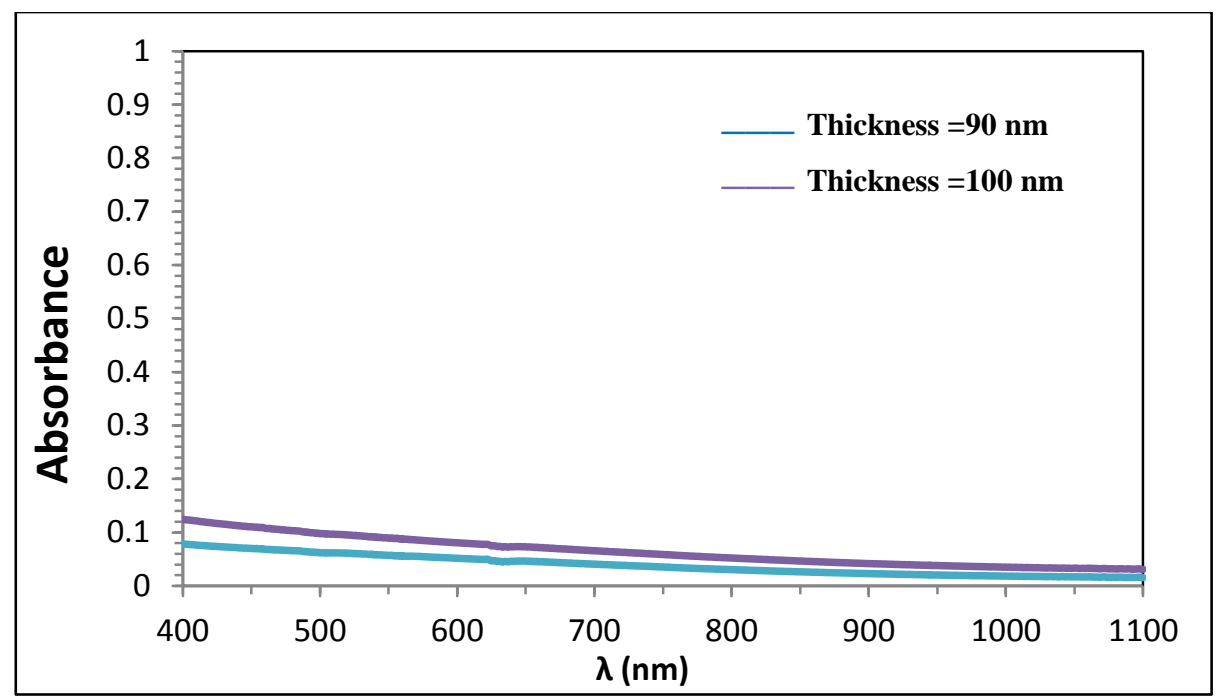

Fig. 3: Absorbance as a function of wavelength for $\mathrm{MgO}$ films of different thicknesses.

This figure shows the absorbance of $\mathrm{MgO}$ films increase with increase thicknesses of layer.

The absorption coefficient $\alpha$ is determined by using Eq. (6) the variation of the absorption coefficient of the $\mathrm{MgO}$ films is a function of wavelength as shown in Fig. 4. The absorption coefficient values are larger than $\left(10^{4} \mathrm{~cm}^{-1}\right)$ for all films. It can be noticed that $\alpha$ in general increases with increasing of thicknesses layers.

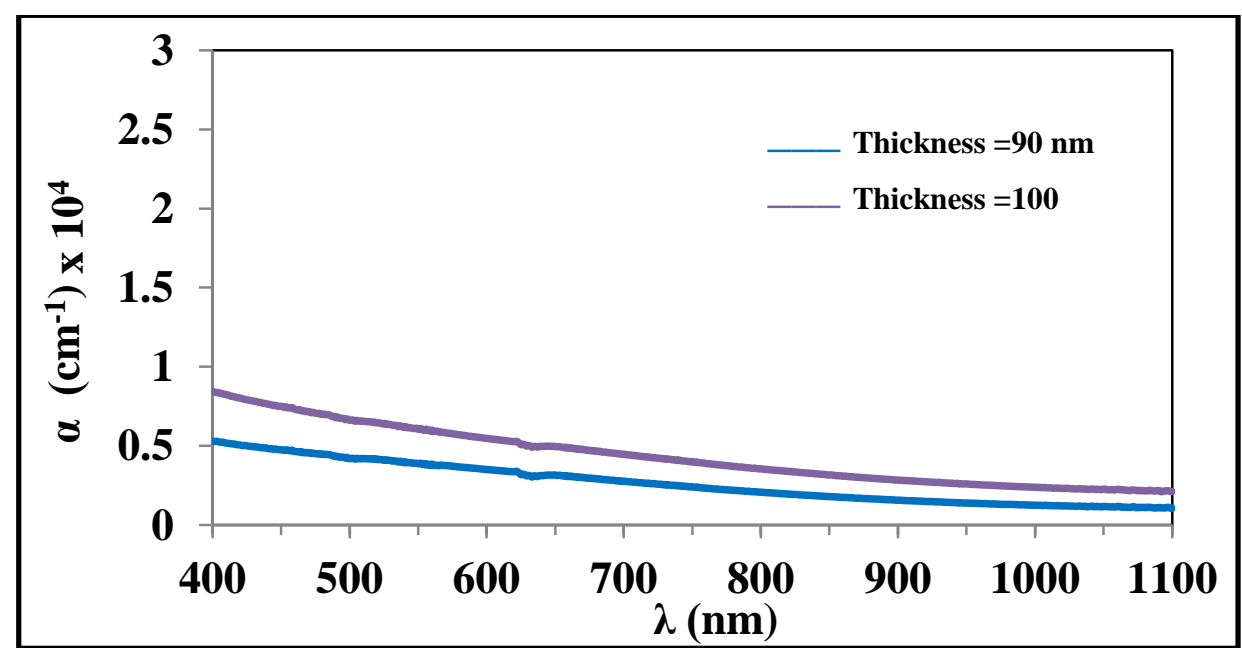

Fig.4: Absorption coefficient ( $\alpha$ ) as a function of wavelength for $\mathrm{MgO}$ films of different thicknesses.

The relation between refractive index and wavelength in the range (400-1100) $\mathrm{nm}$, for different thickness (90 and 100) $\mathrm{nm}$ at annealing temperature $(500 \mathrm{~K})$ are shown in Fig.5. This figure shows dispersion phenomenon. This Figure also, shows the value of the refractive index various with wavelength have value between (1.17 and 1.53). More it can be observed in this Figure that the refractive index increases with increasing film thickness [16]. 


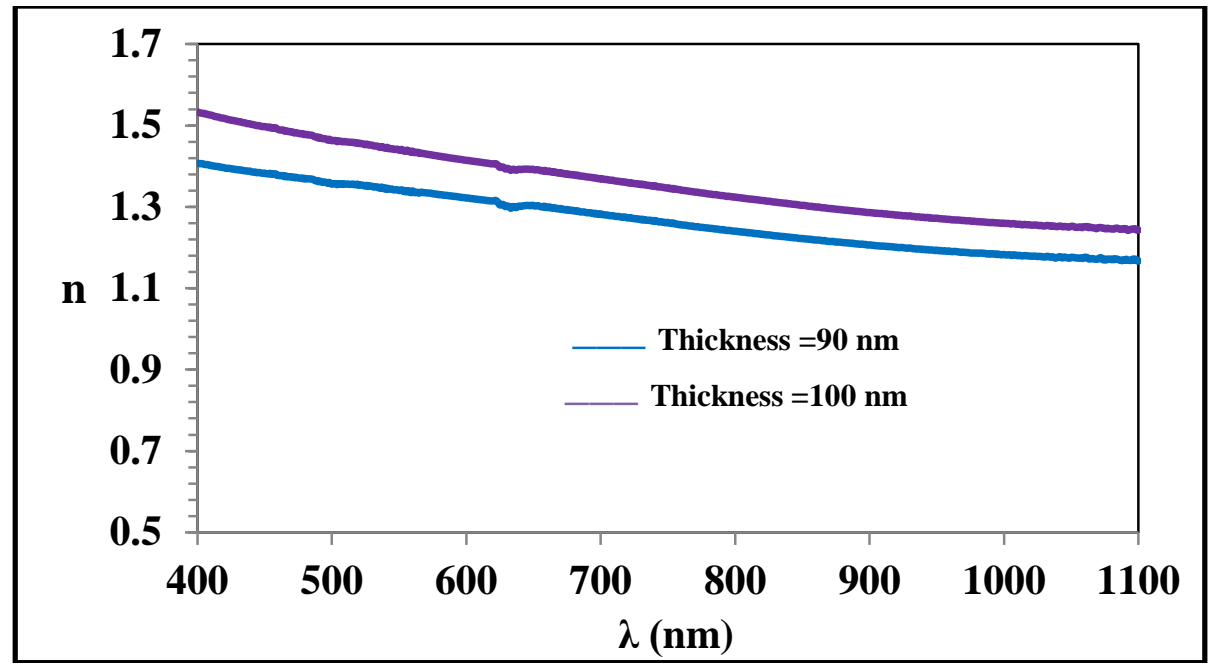

Fig.5: Refractive index as a function of wavelength for MgO films of different thicknesses.

The extinction coefficient $(\mathrm{k})$ is calculated by using Eq. (5). The variation extinction coefficient as a function of wavelength for $\mathrm{MgO}$ thin films with different thicknesses (90 and 100) nm are shown in Fig. 6.

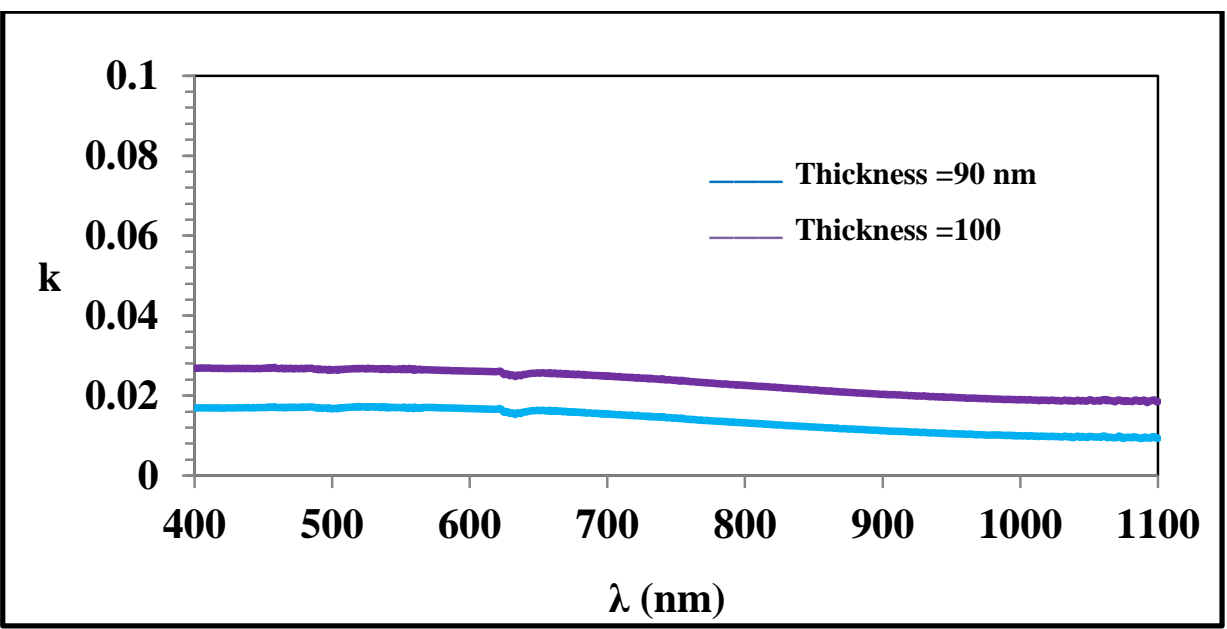

Fig.6: Extinction coefficient as a function of wavelength for $\mathrm{MgO}$ films with different thicknesses.

From this figure it can be noticed that the extinction coefficient $(\mathrm{k})$ takes the similar behavior of the corresponding absorption coefficient. It can also be noticed that the extinction coefficient increases with increasing thicknesses layers [17].
2. Fabricating and comparing between experiment and theoretical optical performances of $A R^{\prime} C$.

The optical performance of AR'C is computed with the aid of Eq. (2) and MATLAB over the wavelength range (400-1100 nm) with thicknesses films (90 and 100) $\mathrm{nm}$ and accredited on optical constants (n, k) of films as shown in Fig. 7. 


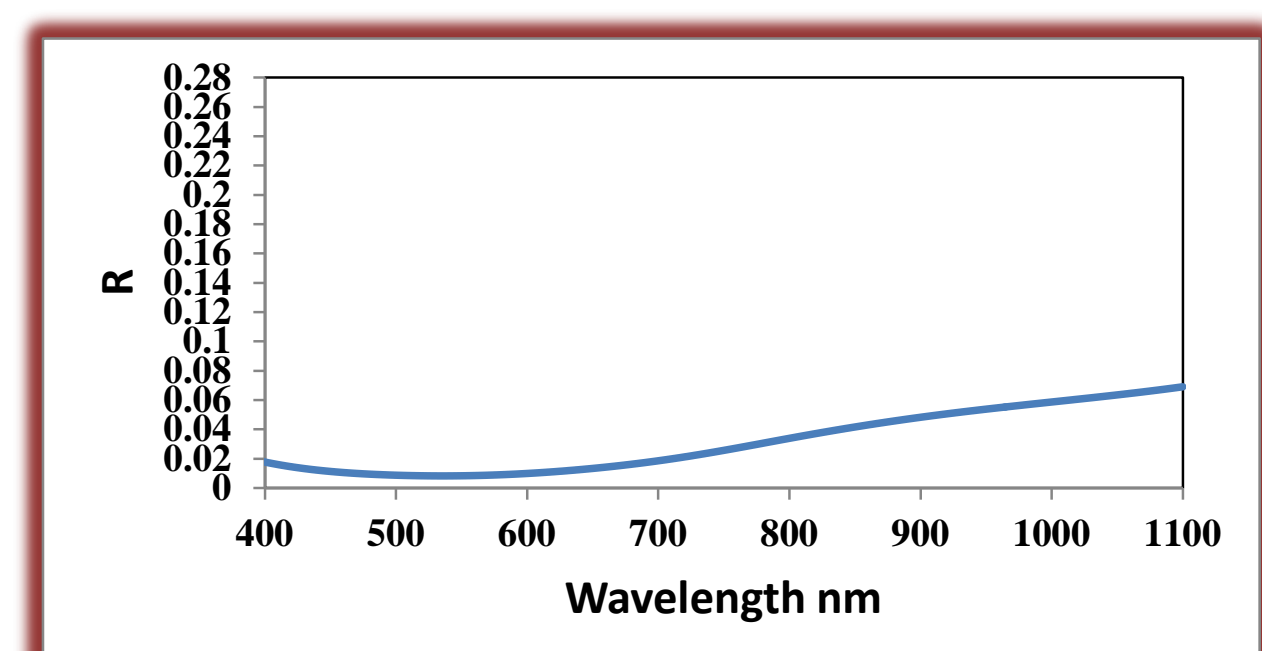

(a)

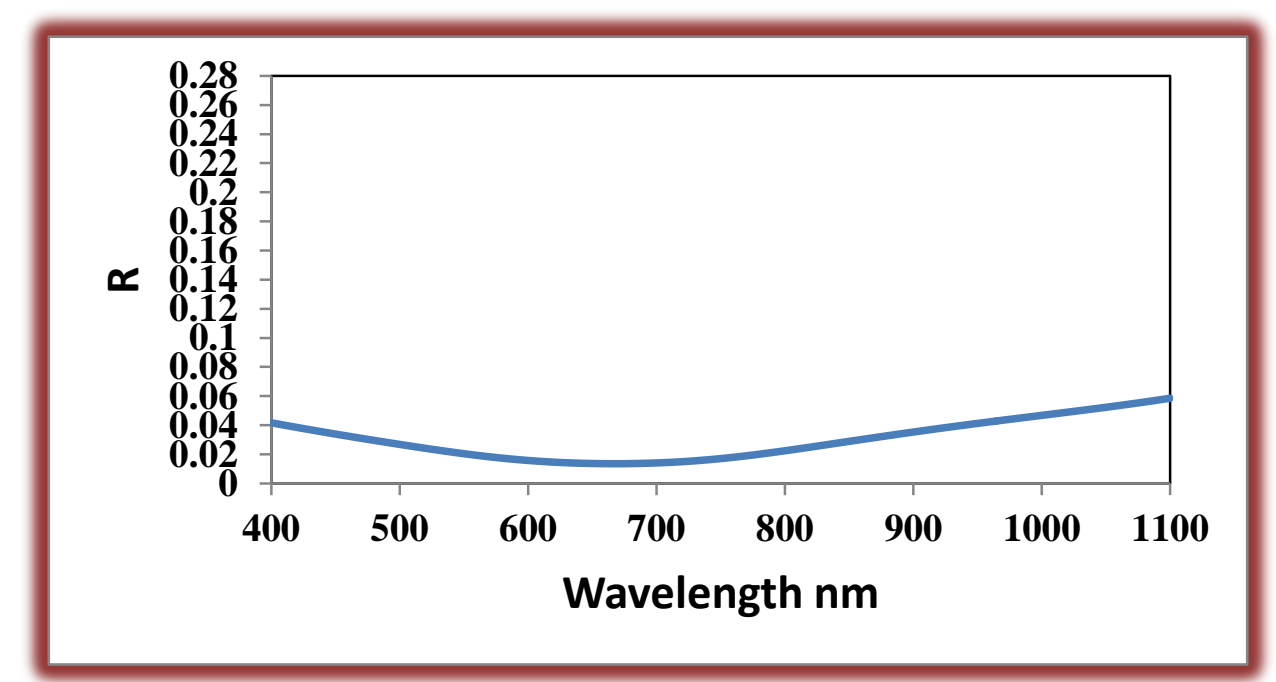

(b)

Fig.7: Optical performance of $A R^{\prime} C$ for experiment result for thicknesses (a:90 nm, b:100 $\mathrm{nm}$ ).

This Figure shows fabricated $\mathrm{AR}^{\prime} \mathrm{C}$ for visible - near IR region at shots number (700 and 800) and thickness $(90,100) \mathrm{nm}$ respectively.

Fig. 7(a) shows optical performance of AR'C with low reflection at design wavelength $(550 \mathrm{~nm})$ at 700 shots and 90nm. While Fig. 7(b) shows to AR'C with low reflection at wavelength $668 \mathrm{~nm}$.
The comparison of optical performances between experiment and theoretical results for sample of shots number 700 at $90 \mathrm{~nm}$ thickness are shown in Fig. 8. This Figure shows convergence between experiment and theoretical results in two region visible and near IR. 


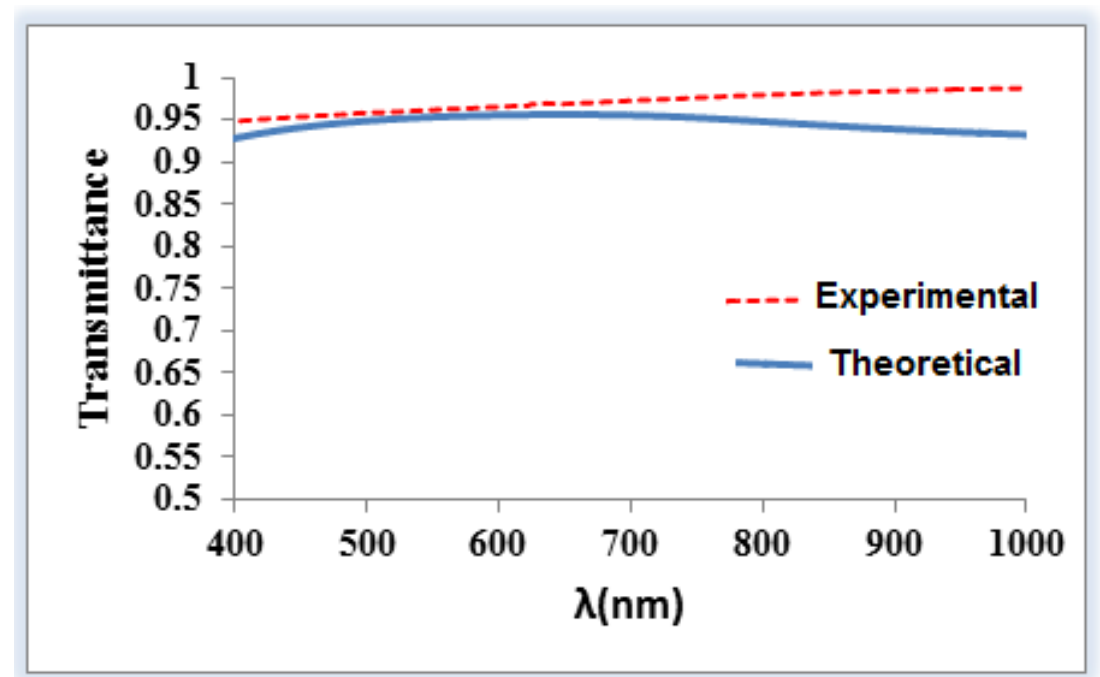

Fig.8: comparison of optical performances for $A R^{\prime} C$ between experiment result (.......) and theoretical results (-) at $(90 \mathrm{~nm})$ thickness.

3. X-ray diffraction (XRD) for MgO thin films

XRD study was carried out in order to get an idea about the structure of $\mathrm{MgO}$ thin film prepared by PLD techniques. The X-ray diffraction measurement was carried out on $\mathrm{MgO}$ thin films deposits at number of shot equal to (700 shot of $90 \mathrm{~nm}$ thickness).

Fig.9 and Table 1 explain the structure of annealed film which found to be polycrystalline structure for sample with the dominant orientation in the (200) direction and weak peak at (111) and (220). Result of XRD is compared with standard (96-901-3272). It can be observed that significant in crystalline is cleared. The X-ray diffraction data of thin film coincides with that of the known polycrystalline cubic $\mathrm{MgO}$ peak.

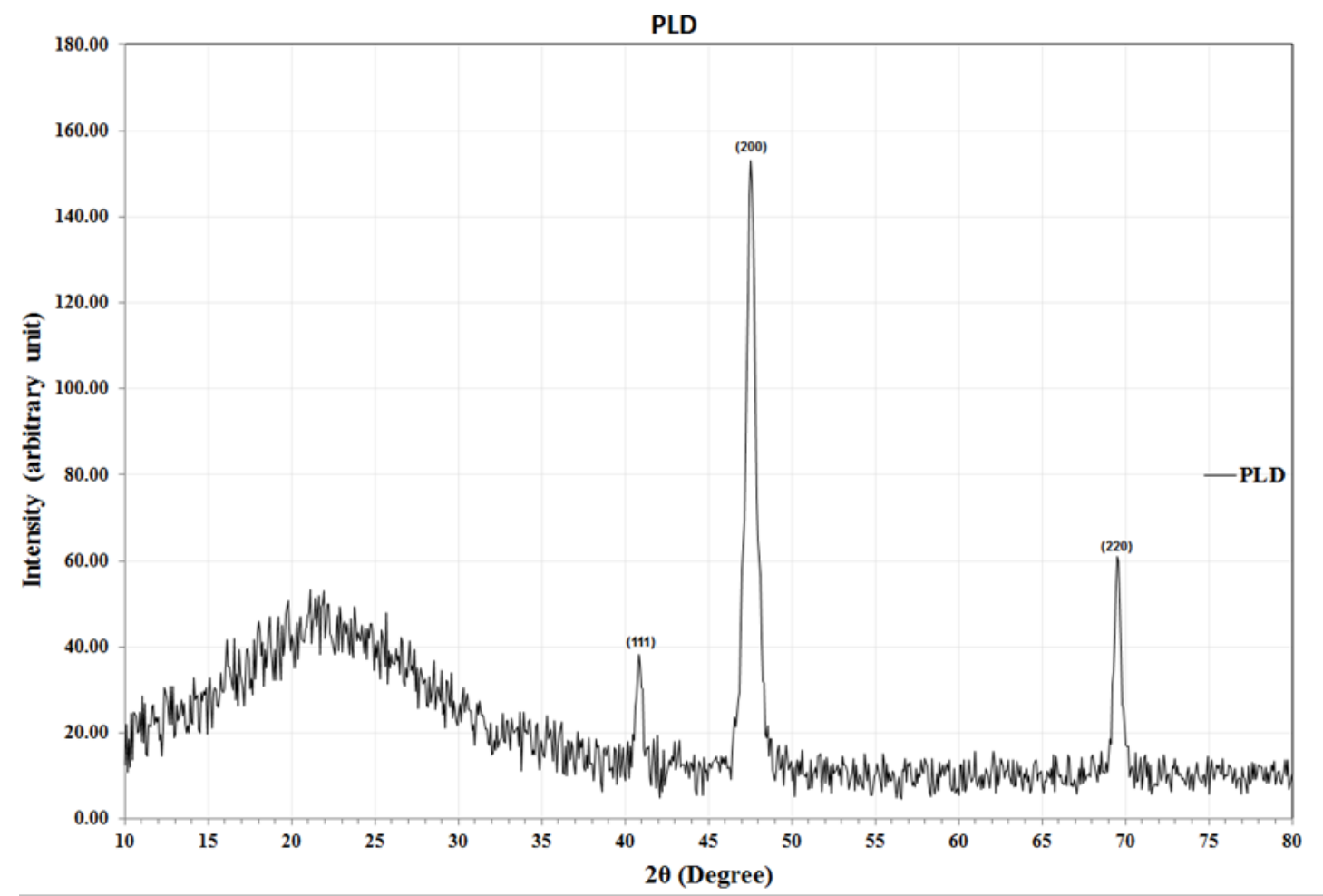

Fig .9: X-ray diffraction for $\mathrm{MgO}$ thin film. 
Table 1: X-ray diffraction for $\mathrm{MgO}$ thin film.

\begin{tabular}{|c|c|c|c|c|c|}
\hline $2 \theta$ (Deg.) & $\begin{array}{c}\text { FWHM } \\
(\text { Deg.) }\end{array}$ & $\mathrm{d}_{\text {hkl }}$ Exp.( $(\AA)$ & C.S (nm) & hkl & $\mathrm{d}_{\text {hkl }}$ Std. $(\AA)$ \\
\hline 40.8870 & 0.3100 & 2.2054 & 27.4 & $(111)$ & 2.2061 \\
\hline 47.5580 & 0.4210 & 1.9104 & 20.6 & $(200)$ & 1.9105 \\
\hline 69.5430 & 0.5130 & 1.3507 & 18.9 & $(220)$ & 1.3509 \\
\hline
\end{tabular}

\section{Conclusions}

There is a fabricated AR'C at annealing temperature $(500 \mathrm{~K})$ and Number of shots (700 and 800). The optical performance of $\mathrm{AR}^{\prime} \mathrm{C}$ with low reflection at design wavelength $(550 \mathrm{~nm})$ of 700 shot and wavelength $(668 \mathrm{~nm})$ at 800 shot and the XRD results give the polycrystalline of cubic structure at annealing temperatures and the preferred orientations are (111) (200) (220) for $\mathrm{MgO}$ films.

\section{References}

[1] M.Y. Jinn and Y.K. Cheng, IEEE, 2, (2000) 978-985.

[2] Mit Researchers Create A 2007. "Perfect Mirror". Mit Press Release. 11-26. Retrieved -01-17. 1998.

[3] Alaa Nazar Abd AL-Gaffar Baghdad Science Journal, 8, 2 (2011) 495-502.

[4] D. Lesnic, G. Wakefield, B.D. Sleeman, J.R. Ockendon, Mathematicsin-Industry Case Studies Journal, 2 (2010) 155-173.

[5] T. Hutzler, A. Krell "MgO transparent ceramics with high thermal conductivity" Frunhofer IKTC Report 2013.

[6] N. M. A. Hadia, H. A. H. Mohammed, Materials Science in Semiconductor Processing, 29 (2015) 238-244.

[7] F. Niu, B. H. Hoeman, B. W. Wessels. MRS Proceedings, 619 (2000) 149.
[8] S. S. Lee, "Vapor phase epitaxy of magnesium oxide on silicon using methylmagnesium alkoxides", CVD $\mathrm{XV}$ : Proceedings of the Fifteenth International Symposium on Chemical Vapor Deposition, vol. 2000, pp 277, 2000.

[9] Y. W. Choi, J. Kim, Thin Solid Films, 460 (2004) 295-299.

[10] S. Kaneko, Japanese Journal of Applied Physics, 52, 2 (2012) pp.01A.

[11] J. Boo, Soon- Bo Lee, Kyu-Sang $\mathrm{Yu}$, Wonyong Koh, Yunsoo Kim, Thin Solid Films, 341 (1999) 63-67.

[12] H. A. Macleod, "Thin-Film Optical Filters" (Mcgraw-Hill, New York) 1986.

[13] S. Grall, "Fundamentals of Optics" Mcgraw-Hill, New York, (2001).

[14] F. Sakaguchi and T. Kobayashi, J. Apply. Phys., 234 (2010) 1521-1532.

[15] A. Moldonado, R. Asamoza, C. Ortegaj, R. Hernandez, J. Solar Energy Mater. Sol. Cells, 57, 4 (1999) 331.

[16] J. Wu, W. Walukiewicz, K. M. Yu, J. W. Ager, E. E. Haller, I. Miotkowski, A. K. Ramdas, Ching-Hua Su, I. K. Sou, R. C. C. Perera, J. D. Denlinger, Phys. Rev., B67, 035207 (2003) 3-15. [17] C. Baban and G.I. Rusu Prepelita, J.Opto. Electron. Adv. Mater., 7, 2 (2005) 817. 